\title{
Renal Efflux Transporter Expression in Pregnant Mice with Type 1 Diabetes
}

\author{
Lindsay L. Yacovino ${ }^{a, b}$ and Lauren M. Aleksunes ${ }^{a, c}$ \\ aDepartment of Pharmacology and Toxicology, Rutgers University Ernest Mario School of \\ Pharmacy, 170 Frelinghuysen Rd, Piscataway, NJ, 08854 USA \\ bJoint Graduate Program in Toxicology, Rutgers University/University of Medicine and Dentistry \\ of New Jersey, 170 Frelinghuysen Rd, Piscataway, NJ, 08854 USA \\ 'Environmental and Occupational Health Sciences Institute, a Joint Institute of Robert Wood \\ Johnson Medical School and Rutgers University, 170 Frelinghuysen Rd, Piscataway, NJ, 08854 \\ USA
}

\begin{abstract}
Prior research suggests that sex hormones and metabolic changes, such as obesity and hyperglycemia, can alter renal transporter expression in rodents. The purpose of this study was to characterize the expression of kidney efflux transporters and regulatory transcription factors in response to Type I diabetes and pregnancy. Female C57BL/6 mice were treated with multiple low doses of streptozotocin (STZ) to induce hyperglycemia and then mated with normoglycemic male mice. Transporter mRNA and protein expression were quantified in kidneys from vehicle- and STZ-treated non-pregnant and pregnant mice on gestation day 14. Pregnancy decreased the expression of Mdr1b, Mrp4, and 5 proteins and increased the mRNA and protein expression of Mrp3 by 50 to $60 \%$. STZ treatment elevated Mrp1, 2, 4, and 5 and reduced Mrp3, 6, and Mdr1b mRNA and/or protein in non-pregnant mice. Pregnancy had little effect on STZ-mediated changes in renal efflux transporter expression. Transcriptional profiles of Hnfla, PXR, AhR, and Nrf2 were altered in patterns similar to some efflux transporters suggesting potential involvement in their regulation. Taken together, these results suggest that renal drug efflux transporters and regulatory signaling pathways are altered by endocrine and metabolic changes that occur during pregnancy and Type I diabetes.
\end{abstract}

\section{Keywords}

Diabetes; Mrp; renal transporters; kidney; pregnancy

\footnotetext{
(C) 2012 Elsevier Ireland Ltd. All rights reserved.
}

Send Correspondence to: Lauren Aleksunes, PharmD, PhD, Department of Pharmacology and Toxicology Rutgers University 170 Frelinghuysen Road, Piscataway, NJ, USA., Phone: +1-732-445-5518 Fax: +1-732-445-0119 aleksunes@eohsi.rutgers.edu.

Publisher's Disclaimer: This is a PDF file of an unedited manuscript that has been accepted for publication. As a service to our customers we are providing this early version of the manuscript. The manuscript will undergo copyediting, typesetting, and review of the resulting proof before it is published in its final citable form. Please note that during the production process errors may be discovered which could affect the content, and all legal disclaimers that apply to the journal pertain.

Conflicts of Interest

The authors declare that there are no conflicts of interest. 


\subsection{Introduction}

Type I diabetes (TID) or insulin-dependent diabetes occurs in nearly 0.2 to $0.5 \%$ of all pregnancies (Vargas et al., 2010). In the United States, this translates to approximately 8,000 to 20,000 pregnancies each year. Hyperglycemia increases the risk of miscarriage, preeclampsia, albuminuria, preterm delivery, and nephropathy (Forsbach-Sanchez et al., 2005). Additionally, neonates born to diabetic mothers have elevated risks of congenital anomalies including cardiac, renal, and neural tube defects, macrosomia, and perinatal death (Taylor and Davison, 2007; Yves et al., 2010).

Within the kidneys, persistent hyperglycemia can cause glomerular structural changes, increases in extracellular matrix of the mesangium that alter glomerular surface area, tubular atrophy, and thickening of basement membranes (Vargas et al., 2010). A TID patient is susceptible not only to renal disease, but also to extrarenal injury due to impaired urinary clearance of chemicals. Likewise, pregnancy also alters kidney function. Pregnancy initiates several physiological changes including an increase in cardiac output and renal vasodilation (Cornelis et al., 2011). Vasodilation elevates renal plasma flow by 50 to $80 \%$, increases kidney size, enhances glomerular filtration rate, and can lead to proteinuria, glucosuria, and aminoaciduria (Cornelis et al., 2011; Powe and Thadhani, 2011). In combination, TID and pregnancy can elevate a patient's risk of preeclampsia, proteinuria, and renal disease (Powe and Thadhani, 2011).

Renal transporters are membrane-spanning proteins that facilitate the movement of toxins and drugs from the blood to urine (secretion) or urine to blood (reabsorption), playing a key role in pharmacokinetics. Efflux transporters present within the kidneys are members of the ATP-binding cassette $(\mathrm{ABC})$ superfamily. Renal efflux transporters include multidrug resistance-associated proteins (Mrps), multidrug resistance proteins (Mdrs), and the breast cancer resistance protein (Bcrp) (reviewed in Klaassen and Aleksunes, 2010). Prominent expression of transporters on the apical (Mrp2, Mrp4, Bcrp, Mdr1) and basolateral membranes (Mrp1, 3, 5, 6) of proximal tubule epithelial cells indicates a critical role for these proteins in the reabsorption and excretion of nutrients, toxins, and drugs.

Regulation of hepatic and renal transporters has been investigated in rodent models of diabetes and obesity (Cheng et al., 2008; More and Slitt, 2011). In a study of obese mice with Type II diabetes (ob/ob strain), mRNA and protein expression of uptake transporters were decreased in the liver (Cheng et al., 2008). Compared to normal mice, ob/ob mice have reduced hepatic Mrp1 and 6 and increased Mrp4 mRNA and protein expression. In kidneys of ob/ob mice, levels of Mrp3 mRNA were reduced and expression of Mrp4 mRNA was elevated (Cheng et al., 2008). In addition, $\mathrm{db} / \mathrm{db}$ mice, which have a mutated leptin receptor and marked hyperglycemia, have similar changes in renal transporter expression including down-regulation of Mrp3 mRNA in female mice and up-regulated Mrp3 and 4 mRNA in male mice (More et al., 2012). It is important to note that mice fed a high fat diet exhibit only mild hyperglycemia and relatively constant renal transporter expression, suggesting that the extent of glucose changes may be critical in transcriptionally regulating efflux transporter genes (More and Slitt, 2011). These data suggest that metabolic and endocrine dysregulation, such as diabetes and obesity, can alter transporter expression in the liver and kidneys.

Little is known about the regulation of renal transporters during pregnancy. In a study of 13 pregnant patients, enhanced urinary clearance of the cardiac glycoside digoxin raised the possibility that renal MDR1 activity is increased during pregnancy (Hebert et al., 2008). Rodent studies have largely focused on hepatic transporters, which undergo a global decline in mRNA and protein expression during pregnancy (Cao et al., 2002). It is unclear whether 
pregnancy also alters levels of transporters in the kidneys. Nonetheless, prior studies demonstrate the ability of sex hormones to mediate gender differences in mouse kidney transporter expression and strongly support the potential for pregnancy to similarly regulate these genes (Cheng and Klaassen, 2009; Maher et al., 2006a).

Given the maternal and fetal risks associated with TID during pregnancy, it is important to identify changes in renal transporter expression that could influence the excretion and toxicity of drugs, toxins, and endogenous chemicals. Therefore, the goals of the current study were to 1) quantify the mRNA and protein expression of efflux transporters in kidneys of adult female mice in response to streptozotocin (STZ)-induced TID and pregnancy, 2) determine whether pregnancy alters transporter changes in response to STZ, and 3) identify potential regulatory pathways responsible for differential renal gene expression. Candidate regulators include the transcription factors nuclear factor E2-related factor 2 (Nrf2), hepatocyte nuclear factor 1 alpha (HNF1a), aryl hydrocarbon receptor (AhR), constitutive androstane receptor (CAR), peroxisome proliferator activated receptor alpha (PPARa), and pregnane $\mathrm{X}$ receptor (PXR) that have previously been shown to regulate efflux transporter expression in rodent liver and kidneys (Aleksunes et al., 2010; Maher et al., 2005; Maher et al., 2006b).

\subsection{Methods}

\subsubsection{Animals}

Adult female and male C57BL/6 mice were obtained from Charles River Laboratories (Wilmington, MA). Mice were provided food and water ad libitum. Female mice were injected intraperitoneally with citrate buffer $(0.01 \mathrm{M}, \mathrm{pH} 4.5)$ vehicle or $\mathrm{STZ}(50 \mathrm{mg} / \mathrm{kg} / \mathrm{d}, 5$ $\mathrm{ml} / \mathrm{kg}$ ) (Sigma, St. Louis, MO) for 4 consecutive days. STZ-treated mice were considered diabetic when blood glucose levels peaked over $250 \mathrm{mg} / \mathrm{dl}$ on two consecutive occasions. Up to two additional doses of STZ were administered to female mice to achieve sustained blood glucose levels over $250 \mathrm{mg} / \mathrm{dl}$. Blood glucose levels were assessed from tail vein blood using a TRUEtrack glucometer in non-fasted mice (Home Diagnostics, Fort Lauderdale, FL). After at least two weeks of hyperglycemia, STZ-treated as well as vehicletreated female mice were mated overnight with normoglycemic male C57BL/6 mice until a vaginal plug was observed (denoting gestation day 0 ). At gestation day 14, terminal body and kidney weights were recorded for pregnant and time-matched non-pregnant mice. Terminal serum glucose levels were quantified using a Glucose LiquiColor kit (Fisher, Pittsburgh, PA). Portions of kidneys and pancreas were either snap frozen or fixed in formalin for mRNA, protein, histological and immunofluorescence analyses. The Rutgers University Institutional Animal Care and Use Committee approved these studies.

\subsubsection{Histology}

Kidney and pancreas samples were fixed in $10 \%$ neutral-buffered formalin and embedded in paraffin. Tissues were sectioned into $5 \mu \mathrm{m}$ thick sections and stained with hematoxylin and eosin. Sections were examined by light microscopy for renal and pancreatic pathology

(Aleksunes et al., 2008a).

\subsubsection{RNA Isolation and Purification}

Total RNA was isolated from half of a kidney by phenol-chloroform extraction using RNABee (Fisher, Pittsburgh, PA) and purified using the RNeasy mini kit (Qiagen, Valencia, CA). RNA concentrations were determined at $260 \mathrm{~nm}$ on a Nanodrop ND 2000 spectrophotometer (Thermoscientific, Wilmington, DE). Formaldehyde-free agarose gel electrophoresis was used to confirm RNA integrity. 


\subsubsection{Real-time Quantitative PCR (qPCR)}

One microgram of total RNA was converted to single-stranded cDNA using olig(T) ${ }_{18}$ primers. mRNA was then quantified by real-time qPCR using primers indicated in Supplementary Table 1 and Power SYBR Green PCR Master Mix (Applied Biosystems, Foster City, CA) and analyzed on an ABI7900HT PCR System (Applied Biosystems, Carlsbad, CA). Target gene expression was normalized to the level of the housekeeping gene, ribosomal protein L13A (Rpl13a), and expressed as fold changes.

\subsubsection{Western Blot Analysis}

Kidney protein samples were prepared by homogenizing half of a kidney in $500 \mu \mathrm{L}$ of Sucrose-Tris buffer composed of $250 \mathrm{mM}$ sucrose and $10 \mathrm{mM}$ Tris- $\mathrm{HCl}$ at $\mathrm{pH} 7.5$ and protease inhibitor cocktail (Sigma Chemical Co., St. Louis, MO). Total protein concentration was determined by the BCA assay (Thermo Fisher Scientific, Rockford, IL). Western blot was used to assess relative efflux transporter expression (Aleksunes et al., 2008a). Fifty $\mu \mathrm{g}$ of protein homogenates were electrophoretically separated on 4-12\% BisTris gels, transferred to PVDF membranes, and stained for transport proteins (Invitrogen). Equal protein loading was confirmed using $\beta$-actin as a loading control (Ab8227, Abcam, Cambridge, MA). Antibodies included: Mrp1 (MRPr1, Alexis, Farmingdale, NY), Mrp2 ( $\mathrm{M}_{2} \mathrm{III}-5$, Alexis), Mrp3 ( $\mathrm{M}_{3} \mathrm{II}-2 \mathrm{G}$. Scheffer, VU Medical Center, Amsterdam, the Netherlands), Mrp4 (M41-10, Alexis), Mrp5 (M $\mathrm{M}_{5} 1-10$, G. Scheffer), Mrp6 (M $\mathrm{M}_{6} \mathrm{II}-68$, G. Scheffer), Bcrp (BXP-53, Alexis), and Mdr1a/b (C219, Abcam). After incubation with secondary antibodies, antibody-protein complexes were detected and quantified using a Fluorochem imager (Alpha Innotech, San Leandro, CA).

\subsubsection{Immunofluorescence Staining}

Indirect immunofluorescence staining of efflux transporters on frozen mouse tissue sections has been reported previously (Aleksunes et al., 2008b; Aleksunes et al., 2006). Images were acquired on a Zeiss Observer D1 microscope with a X-cite series 120Q fluorescent illuminator (Zeiss Inc., Thornwood, NY) and a Jenoptik camera with ProgRes CapturePro 2.8 software (Jenoptik, Easthampton, MA). Images were cropped and brightness and contrast were adjusted equally for each antibody in Adobe Photoshop CS2 (San Jose, CA). Negative controls without antibody were included (data not shown).

\subsubsection{Statistical Analysis}

Statistical analysis was performed using GraphPad Prism@ $\odot$ version 5 software (GraphPad, La Jolla, CA). Differences among these groups were evaluated by one-way ANOVA followed by Newman-Keul's multiple-range post hoc test and $\mathrm{p} \unlhd 0.05$ were considered statistically significant.

\subsection{Results}

\subsubsection{Kidney Weights, Histology, and Serum Glucose in Diabetic Pregnancy}

Total body weights were nearly $50 \%$ higher in pregnant mice compared to non-pregnant mice, regardless of STZ treatment (data not shown). Similarly, kidney weights of pregnant mice were about $25 \%$ higher than those of non-pregnant mice (data not shown). Kidney sections showed normal histology in all groups (Supplemental Figure 1). STZ treatment increased serum glucose levels 2.5- to 2.8-fold in both non-pregnant and pregnant mice (Figure 1). Histopathological analysis of pancreas sections by a veterinary pathologist revealed diminished islets of Langerhans in STZ-treated mice that correlated with reduced circulating insulin levels (data not shown). 


\subsubsection{Renal mRNA Expression of Efflux Transporters in Diabetic Pregnancy}

Figure 2 illustrates the renal mRNA expression of apical (Mrp2, Mrp4, Mdr1b, Bcrp, Figure 2A) and basolateral (Mrp1, 3, 5, 6, Figure 2B) transporters in vehicle- and STZ-treated mice during pregnancy. Mdr1b mRNA expression was unaffected by STZ treatment and pregnancy alone but was reduced $40 \%$ in STZ-treated pregnant mice. Messenger RNA expression patterns were similar for Mrp2 and 5. STZ treatment increased Mrp2 and 5 mRNA by 50 to $70 \%$ in non-pregnant and pregnant mice. Like Mrp2 and 5, there was a trend for increased Mrp4 mRNA expression in response to STZ treatment that was somewhat attenuated by pregnancy. Mrp3 mRNA increased $40 \%$ in pregnant mice but was down-regulated 20-60\% in response to STZ treatment in both non-pregnant and pregnant mice. Mrp1, Mrp6, and Bcrp mRNA were unchanged with pregnancy or STZ treatment. Expression of other efflux transporters including the multidrug and toxin extrusion protein 1, organic solute transporters $\alpha$ and $\beta$, and ATP-binding cassette transporter 1 were unchanged by STZ and pregnancy (data not shown).

\subsubsection{Renal Efflux Transporter Protein Expression in Diabetic Pregnancy}

Figure 3A illustrates protein expression patterns for apically-located efflux transporters Mdr1b, Bcrp, Mrp2, and Mrp4. Protein expression of Mrp4 was slightly up-regulated in STZ-treated mice. Interestingly, a 40\% decrease in Mrp4 protein was observed in vehicletreated pregnant mice, but not in STZ-treated pregnant mice. Mdr1b protein was downregulated 40-50\% in response to both pregnancy and STZ treatment. Bcrp and Mrp2 protein levels were unchanged although there was a trend for reduced Mrp2 expression in vehicletreated pregnant mice.

Renal protein expression patterns for basolaterally-located efflux transporters Mrp1, 3, 5, and 6 are shown in Figure 3B. STZ treatment increased Mrp1 expression approximately 30 to $50 \%$ in non-pregnant and pregnant mice. Consistent with mRNA levels, Mrp3 protein decreased in STZ-treated non-pregnant mice and increased $60 \%$ in vehicle-treated pregnant mice. Interestingly, Mrp3 protein levels in STZ-treated pregnant mice were similar to vehicle-treated non-pregnant control mice. Protein expression of Mrp5 was up-regulated similarly in STZ-treated non-pregnant and pregnant mice but decreased by $30 \%$ in response to pregnancy alone. Mrp6 protein remained constant in both STZ- and vehicle-treated pregnant mice, however, it decreased about $40 \%$ in STZ-treated non-pregnant mice.

\subsubsection{Immunofluorescent Detection of Renal Efflux Transporters in Diabetic Pregnancy}

Indirect immunofluorescent staining was performed on gestation day 14 kidney sections obtained from vehicle- and STZ-treated mice during pregnancy to determine localization as well as patterns of transporter protein expression. Figure 4 illustrates the immunofluorescent staining of Mrp1, 3, 4, and 6 proteins in renal sections. Mrp1 staining was on the basolateral membrane of isolated cortical tubule cells and increased significantly with STZ treatment. Additionally, Mrp1 immunofluorescence was observed in the medulla, most likely on the Loops of Henle, and exhibited similar induction with STZ treatment (data not shown). Immunofluorescent staining of Mrp3 was observed on the basolateral membrane of S3 proximal tubule cells at the corticomedullary junction. Staining of Mrp3 was reduced in kidney sections from STZ-treated mice and markedly increased in proximal tubules of pregnant mice. Mrp4 protein staining was observed on the apical membrane of S1 and S2 proximal tubules. Compared to vehicle-treated non-pregnant mice, staining of Mrp4 was slightly greater in STZ-treated mice, however decreased staining was evident in kidneys of vehicle-treated pregnant mice. Immunofluorescent staining of Mrp6 occurred on the basolateral membrane of cortical S1 and S2 proximal tubules. A noticeable decrease in Mrp6 staining was observed in STZ-treated non-pregnant mice. No changes were observed 
for Mrp2 and Bcrp protein staining while Mrp5 immunofluorescence could not be detected (data not shown).

\subsubsection{Renal mRNA Expression of Transcription Factors and Target Genes in Diabetic Pregnancy}

To delineate potential regulatory pathways underlying the observed mRNA changes in transporter expression in response to diabetes and pregnancy, the mRNA of a number of transcription factors and their target genes were quantified. AhR, Hnfla, and PXR mRNA levels increased with pregnancy by about 50\% (Figure 5). Expression of PPARa mRNA remained constant in vehicle-treated groups, however, was down-regulated slightly in kidneys of STZ-treated mice. mRNA expression of CAR and the cytochrome P450 (Cyp) genes, Cyp1a1 (AhR target), Cyp2b10 (CAR target), and Cyp3a13 (PXR target) were too low for quantification. Expression of the PPARa target gene, Cyp4a14, decreased 25\% in STZ-treated non-pregnant mice but was increased between $30-60 \%$ in response to pregnancy (data not shown).

mRNA expression of oxidative defense enzymes heme oxygenase-1 (Ho-1) and $\mathrm{NAD}(\mathrm{P}) \mathrm{H}$ :quinone oxidoreductase 1 (Nqo1) and their transcriptional regulator, $\mathrm{Nrf} 2$, were quantified in kidneys of vehicle- and STZ-treated mice during pregnancy (Figure 6). Nrf2, Nqo1, and Ho-1 all demonstrated a similar pattern of mRNA expression. STZ-induced Nrf2 mRNA in non-pregnant and pregnant mice by $20 \%$ and $40 \%$, respectively. Likewise, Ho- 1 and Nqo1 mRNA expression increased by 2.5- and 1.5-fold, respectively, with STZ treatment. Additionally, Ho- 1 mRNA increased $80 \%$ in vehicle-treated pregnant mice and was markedly elevated (4-fold) in STZ-treated pregnant mice. Although Nqo1 mRNA was unchanged by pregnancy alone, it remained elevated $70 \%$ in STZ-treated pregnant mice.

\subsection{Discussion}

The current study investigated the influence of TID and pregnancy, separately and in combination, on renal efflux transporter mRNA and protein expression in mice. Expression of Mrp3 was increased in pregnancy and reduced by TID and mirrored expression of AhR, HNF1a, and PXR mRNA. Likewise, levels of Mrp1, Mrp4, and Mrp5 were up-regulated by STZ treatment in a manner similar to Nrf2 and its target genes Nqo1 and Ho-1. In some cases, such as Mrp3-5, efflux transporters were regulated by diabetes and pregnancy in opposing directions. Pregnancy had little effect on STZ-induced changes in transporter expression, with the exception of normalizing Mrp4 protein to control levels. Collectively, these data indicate that TID and pregnancy differentially regulate renal transporter expression in female mice, often in an isoform-specific manner (Figure 7).

The STZ model of experimental diabetes was selected for the present study because it causes selective destruction of pancreatic beta cells, reduces insulin levels, and leads to hyperglycemia. Most genetically-altered mice with diabetes ( $\mathrm{db} / \mathrm{db}$ and ob/ob mice) are infertile, which precludes investigation of pregnancy-mediated transporter changes. STZ treatment and subsequent hyperglycemia had no effect on mouse fecundity (data not shown) and was the most appropriate model to study renal transporter regulation in pregnancy and TID. This study demonstrates that efflux transporter mRNA expression is altered in kidneys of female mice treated with STZ. Expression of Mrp2 and 4 transporters increased in STZtreated mice, similar to male rats with type 2 diabetes (Nowicki et al., 2008). Basolaterallylocated transporters displayed a slightly different pattern of expression. Kidneys of STZtreated mice had increased expression of Mrp1 and 5 proteins and decreased expression of Mrp3 protein. A similar down-regulation of Mrp3 mRNA has been observed in female ob/ ob mice (Cheng et al., 2008). In addition to changes in efflux transporters, the expression of some uptake carriers was increased (organic anion transporting polypeptide $2 \mathrm{~b} 1 \mathrm{and} 4 \mathrm{c} 1$ ) or 
decreased (organic anion transporter 2 and 5) in response to STZ treatment (data not shown). Taken together, these results demonstrate changes in renal transporters in response to TID that are often similar to other rodent models of diabetes.

Studies of renal transporter changes in rodents and humans during pregnancy are limited. For the present study, gestation day 14 was selected for analysis because it is the time point when most hepatic transporters are down-regulated in pregnant mice (data not shown). Our study suggests that pregnancy only modestly influences renal transporter expression at this time point. Regulation of efflux transporters in kidneys of pregnant mice was somewhat complicated by some changes occurring only at the protein level (down-regulation of Mdr1b, Mrp4, Mrp5) or both the mRNA and protein levels (up-regulation of Mrp3). The reason behind the discordance between mRNA and protein expression for some transporters is unclear; however, it can be hypothesized that pregnancy may alter protein levels through post-transcriptional or post-translational mechanisms. Likewise, changes in mRNA expression may have occurred at earlier time points and not detected at gestation day 14 in the current study.

Potential signaling pathways responsible for renal transporter regulation during pregnancy and diabetes were assessed by mRNA analysis. Transcription factors (AhR, CAR, PXR, PPARa, Nrf2, HNF1a) were selected based upon prior evidence that they regulate drug transporters in the liver and/or kidneys in null mouse models or following pharmacological activation (reviewed in Klaassen and Aleksunes, 2010). Attempts were made to quantify known target genes of these transcription factors, although expression of Cyp enzymes was low in kidneys. AhR, PXR, and HNF1a mRNAs were increased in the kidneys of vehicletreated pregnant mice; however, this induction was attenuated in STZ-treated pregnant mice. Interestingly, this pattern of expression mirrors Mrp3 mRNA and protein levels and each of these transcription factors have been previously implicated in directly or indirectly regulating Mrp3 (Maher et al., 2005; Maher et al., 2006b). Prior studies by our laboratory and others have demonstrated the ability of the oxidative stress sensor, Nrf2, to regulate renal and hepatic transporters (Aleksunes et al., 2010; Aleksunes et al., 2008c). Likewise, Nrf2 has been shown to be important in a number of rodent diabetic disease models, including nephropathy and cardiomyopathy (He et al., 2009; Jiang et al., 2010). High glucose levels within renal tubules increase production of reactive oxygen species, decrease antioxidants, and activate Nrf2 (Delmastro and Piganelli, 2011; Stanton, 2011). In the current study, Nrf2, as well as its target genes Ho-1 and Nqo1, increased in response to STZinduced diabetes. Transporters that were induced by STZ treatment included Mrp1, 2, 4, and 5, which have previously been identified as Nrf2 targets (Aleksunes et al., 2008c; Maher et al., 2005). It should be noted that Mrp3 mRNA was not induced by STZ, despite prior studies in the liver demonstrating a key role for Nrf2 in regulating hepatic up-regulation of this transporter during oxidative stress (Maher et al., 2008; Maher et al., 2007). The differential regulation of Mrp3 mRNA between the liver and kidneys should be investigated in greater depth. It should be noted that down-regulation of Mrp3 by STZ is consistent with a recent report demonstrating similar findings in female $\mathrm{db} / \mathrm{db}$ diabetic mice (More et al., 2012). Collectively, these data identify AhR, PXR, HNF1a, and Nrf2 as candidate transcription factors for regulating renal transporter expression during TID and pregnancy. Direct involvement of these transcription factors needs to be tested using null mice lacking these genes.

There are some limitations with the experimental design of this study. The present study was designed to first establish hyperglycemia for 2 weeks and then to mate normal and diabetic mice with normoglycemic males. Other labs have administered STZ directly to pregnant dams to induce gestational diabetes. However, we elected to stimulate hyperglycemia prior to pregnancy and avoid the direct chemical effects of STZ on the dams as a confounder to 
the study. In turn, the present study may have some applicability to gestational diabetes, but this should be tested further.

In the present study, the majority of changes in mRNA and protein expression were modest which makes the clinical relevance of these findings unknown. It should be noted that pregnancy and TID increase urine formation and glomerular filtration that may obfuscate some changes in efflux transporter expression and activity. On the other hand, modest changes in chemical disposition during pregnancy may be important because it represents a critical period of fetal susceptibility. It should also be noted that there is overlap in the substrate preferences of some transporters. Therefore, even modest changes in transporter expression may be additive if redundant transporters are regulated in a similar fashion. For example, Mrp4 and 5 share substrates and were regulated in a similar fashion in this study (induction with STZ; reduction with pregnancy). However, these two transporters are on opposing membranes (Mrp4: apical and Mrp5: basolateral). Similar regulation of Mrp4 and 5 could result in enhanced renal exposure of shared substrates during pregnancy. Additional work should also examine the functional activity of transporters differentially expressed in this study using isoform-specific and isoform-overlapping substrates. Nonetheless, efflux transporters in the kidneys are key determinants of toxicant accumulation in tubule cells of the nephron and altered expression during diabetes and pregnancy may be important for assessing susceptibility to chemical-induced renal injury.

\subsection{Conclusion}

Messenger RNA and protein expression of a number of renal transporters were regulated by TID and pregnancy in female mice, which suggests the potential for altered drug pharmacokinetics and susceptibility to nephrotoxicity. Correlation of transporter and regulatory mRNAs provides candidate pathways for subsequent investigation to definitively determine their involvement in kidney transporter regulation in pregnant and diabetic mice. Overall, this study provides mechanistic insight into the regulation of uptake and efflux transporters during diabetes and pregnancy, conditions known to alter renal function, urinary excretion, and susceptibility to disease and toxicity.

\section{Supplementary Material}

Refer to Web version on PubMed Central for supplementary material.

\section{Acknowledgments}

The authors would like to thank Dr. Michael Goedken for histopathological analysis, Mrs. Myrna Trumbauer for collection of tissues, Dr. Angela Slitt and Dr. Jason Richardson for qPCR primer sequences, and graduate students and fellows of the Aleksunes laboratory for their contributions to this project.

This work was supported by the National Institutes of Health Institute of Diabetes and Digestive and Kidney Diseases [Grant R01DK080774] and the National Institutes of Environmental Health Sciences [Grants R01ES020522], components of the National Institutes of Health. This research was supported in part by the NIEHS-sponsored UMDNJ Center for Environmental Exposures and Disease, P30ES005022 and NIEHSsponsored Training in Environmental Toxicology, T32ES007148.

\section{Non-Standard Abbreviations}
Abc
ATP-binding cassette
Abca
ATP-binding cassette transporter
AhR
aryl hydrocarbon receptor 


$\begin{array}{ll}\text { Bcrp } & \text { breast cancer resistance protein } \\ \text { CAR } & \text { constitutive androstane receptor } \\ \text { Cyp } & \text { cytochrome P450 } \\ \text { HNF1a } & \text { hepatocyte nuclear factor 1a } \\ \text { Ho-1 } & \text { heme oxygenase-1 } \\ \text { Mdr } & \text { multidrug resistance protein } \\ \text { Mrp } & \text { multidrug resistance-associated protein } \\ \text { Nqo1 } & \text { NAD(P)H:quinone oxidoreductase 1 } \\ \text { Nrf2 } & \text { nuclear factor E2-related factor 2 } \\ \text { PPARa } & \text { peroxisome proliferator-activated receptor a } \\ \text { PXR } & \text { pregnane X receptor } \\ \text { Rpl13a } & \text { ribosomal protein 13a } \\ \text { STZ } & \text { streptozotocin } \\ \text { TID } & \text { type I diabetes }\end{array}$

\subsection{References}

Aleksunes LM, Augustine LM, Scheffer GL, Cherrington NJ, Manautou JE. Renal xenobiotic transporters are differentially expressed in mice following cisplatin treatment. Toxicology. 2008a; 250:82-88. [PubMed: 18640236]

Aleksunes LM, Cui Y, Klaassen CD. Prominent expression of xenobiotic efflux transporters in mouse extraembryonic fetal membranes compared with placenta. Drug Metab Dispos. 2008b; 36:19601970. [PubMed: 18566041]

Aleksunes LM, Goedken MJ, Rockwell CE, Thomale J, Manautou JE, Klaassen CD. Transcriptional regulation of renal cytoprotective genes by $\mathrm{Nrf} 2$ and its potential use as a therapeutic target to mitigate cisplatin-induced nephrotoxicity. J Pharmacol Exp Ther. 2010; 335:2-12. [PubMed: 20605904]

Aleksunes LM, Scheffer GL, Jakowski AB, Pruimboom-Brees IM, Manautou JE. Coordinated expression of multidrug resistance-associated proteins (Mrps) in mouse liver during toxicantinduced injury. Toxicol Sci. 2006; 89:370-379. [PubMed: 16177239]

Aleksunes LM, Slitt AL, Maher JM, Augustine LM, Goedken MJ, Chan JY, Cherrington NJ, Klaassen CD, Manautou JE. Induction of Mrp3 and Mrp4 transporters during acetaminophen hepatotoxicity is dependent on Nrf2. Toxicol Appl Pharmacol. 2008c; 226:74-83. [PubMed: 17935745]

Cao J, Stieger B, Meier PJ, Vore M. Expression of rat hepatic multidrug resistance-associated proteins and organic anion transporters in pregnancy. Am J Physiol Gastrointest Liver Physiol. 2002; 283:G757-766. [PubMed: 12181192]

Cheng Q, Aleksunes LM, Manautou JE, Cherrington NJ, Scheffer GL, Yamasaki H, Slitt AL. Drugmetabolizing enzyme and transporter expression in a mouse model of diabetes and obesity. Mol Pharm. 2008; 5:77-91. [PubMed: 18189363]

Cheng X, Klaassen CD. Tissue distribution, ontogeny, and hormonal regulation of xenobiotic transporters in mouse kidneys. Drug Metab Dispos. 2009; 37:2178-2185. [PubMed: 19679677]

Cornelis T, Odutayo A, Keunen J, Hladunewich M. The kidney in normal pregnancy and preeclampsia. Semin Nephrol. 2011; 31:4-14. [PubMed: 21266261]

Delmastro MM, Piganelli JD. Oxidative stress and redox modulation potential in type 1 diabetes. Clin Dev Immunol. 2011; 2011:593863. [PubMed: 21647409]

Forsbach-Sanchez G, Tamez-Perez HE, Vazquez-Lara J. Diabetes and pregnancy. Arch Med Res. 2005; 36:291-299. [PubMed: 15925019] 
He X, Kan H, Cai L, Ma Q. Nrf2 is critical in defense against high glucose-induced oxidative damage in cardiomyocytes. J Mol Cell Cardiol. 2009; 46:47-58. [PubMed: 19007787]

Hebert MF, Easterling TR, Kirby B, Carr DB, Buchanan ML, Rutherford T, Thummel KE, Fishbein DP, Unadkat JD. Effects of pregnancy on CYP3A and P-glycoprotein activities as measured by disposition of midazolam and digoxin: a University of Washington specialized center of research study. Clin Pharmacol Ther. 2008; 84:248-253. [PubMed: 18288078]

Jiang T, Huang Z, Lin Y, Zhang Z, Fang D, Zhang DD. The protective role of Nrf2 in streptozotocininduced diabetic nephropathy. Diabetes. 2010; 59:850-860. [PubMed: 20103708]

Klaassen CD, Aleksunes LM. Xenobiotic, bile acid, and cholesterol transporters: function and regulation. Pharmacol Rev. 2010; 62:1-96. [PubMed: 20103563]

Maher JM, Aleksunes LM, Dieter MZ, Tanaka Y, Peters JM, Manautou JE, Klaassen CD. Nrf2- and PPAR alpha-mediated regulation of hepatic Mrp transporters after exposure to perfluorooctanoic acid and perfluorodecanoic acid. Toxicol Sci. 2008; 106:319-328. [PubMed: 18757529]

Maher JM, Cheng X, Slitt AL, Dieter MZ, Klaassen CD. Induction of the multidrug resistanceassociated protein family of transporters by chemical activators of receptor-mediated pathways in mouse liver. Drug Metab Dispos. 2005; 33:956-962. [PubMed: 15833929]

Maher JM, Cheng X, Tanaka Y, Scheffer GL, Klaassen CD. Hormonal regulation of renal multidrug resistance-associated proteins 3 and 4 (Mrp3 and Mrp4) in mice. Biochem Pharmacol. 2006a; 71:1470-1478. [PubMed: 16529719]

Maher JM, Dieter MZ, Aleksunes LM, Slitt AL, Guo G, Tanaka Y, Scheffer GL, Chan JY, Manautou JE, Chen Y, Dalton TP, Yamamoto M, Klaassen CD. Oxidative and electrophilic stress induces multidrug resistance-associated protein transporters via the nuclear factor-E2-related factor-2 transcriptional pathway. Hepatology. 2007; 46:1597-1610. [PubMed: 17668877]

Maher JM, Slitt AL, Callaghan TN, Cheng X, Cheung C, Gonzalez FJ, Klaassen CD. Alterations in transporter expression in liver, kidney, and duodenum after targeted disruption of the transcription factor HNF1alpha. Biochem Pharmacol. 2006b; 72:512-522. [PubMed: 16806085]

More, V.; X, W.; Thomas, P.; Aleksunes, L.; Slitt, A. Severe diabetes and leptin resistance causes differential hepatic and renal transporter expression in mice. 2012. Comparative Hepatology In Press

More VR, Slitt AL. Alteration of hepatic but not renal transporter expression in diet-induced obese mice. Drug Metab Dispos. 2011; 39:992-999. [PubMed: 21430232]

Nowicki MT, Aleksunes LM, Sawant SP, Dnyanmote AV, Mehendale HM, Manautou JE. Renal and hepatic transporter expression in type 2 diabetic rats. Drug Metab Lett. 2008; 2:11-17. [PubMed: 19356064]

Powe CE, Thadhani R. Diabetes and the kidney in pregnancy. Semin Nephrol. 2011; 31:59-69. [PubMed: 21266265]

Stanton RC. Oxidative stress and diabetic kidney disease. Curr Diab Rep. 2011; 11:330-336. [PubMed: 21557044]

Taylor R, Davison JM. Type 1 diabetes and pregnancy. BMJ. 2007; 334:742-745. [PubMed: 17413175]

Vargas R, Repke JT, Ural SH. Type 1 diabetes mellitus and pregnancy. Rev Obstet Gynecol. 2010; 3:92-100. [PubMed: 21364860]

Yves J, Valerie V, Katrien VH, Guy M. Birth weight in type 1 diabetic pregnancy. Obstet Gynecol Int. 2010; 2010:397623. [PubMed: 21234396] 


\section{Highlights}

- Renal transporters are differentially regulated by diabetes and pregnancy in mice.

- Pregnancy has minimal effect on diabetes-induced transporter changes.

- Expression of Mrp3 was increased in pregnancy and reduced by diabetes.

- Mrp1, 4, and 5 were increased by diabetes similar to Nrf2 and its target genes. 


\section{Serum Glucose}

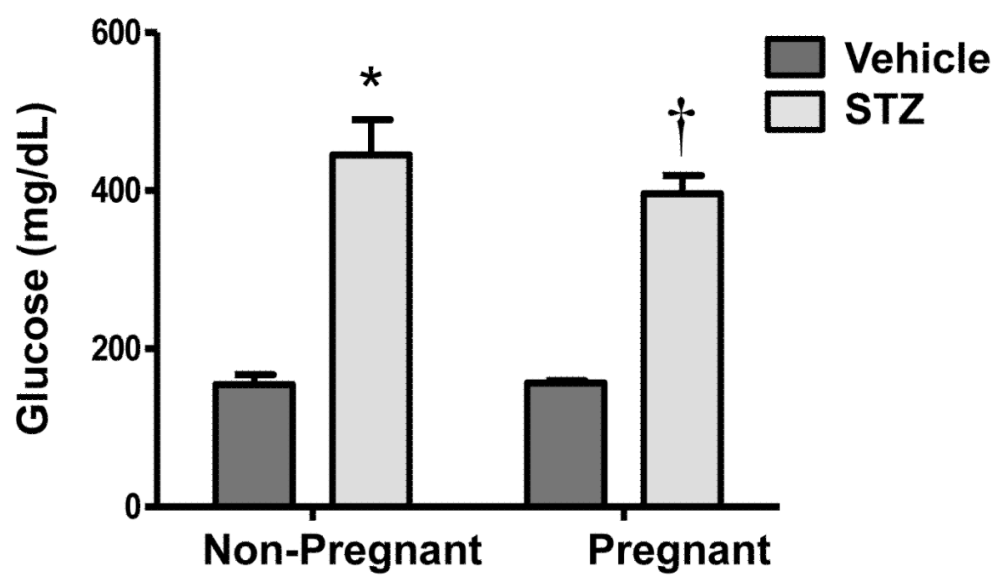

Figure 1. Serum glucose levels in vehicle- and STZ-treated mice during pregnancy Serum glucose levels of vehicle- and STZ-treated fed mice were quantified colorimetrically and presented as mean $\pm \mathrm{SE}(\mathrm{n}=3-8$ animals). Asterisks $(*)$ represent a statistical difference compared to vehicle non-pregnant mice $(\mathrm{p} \leq 0.05)$; Daggers $(\dagger)$ represent a statistical difference between vehicle and STZ-treated pregnant mice ( $\leq 0.05)$; 
A.

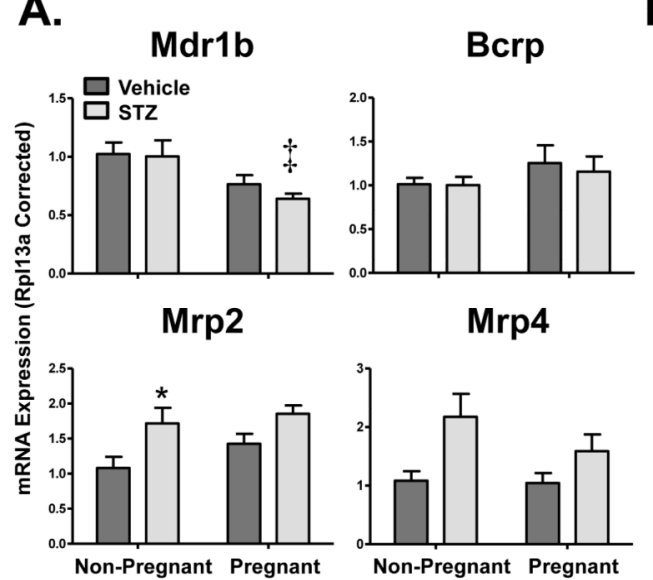

B.

Mrp1

Mrp3
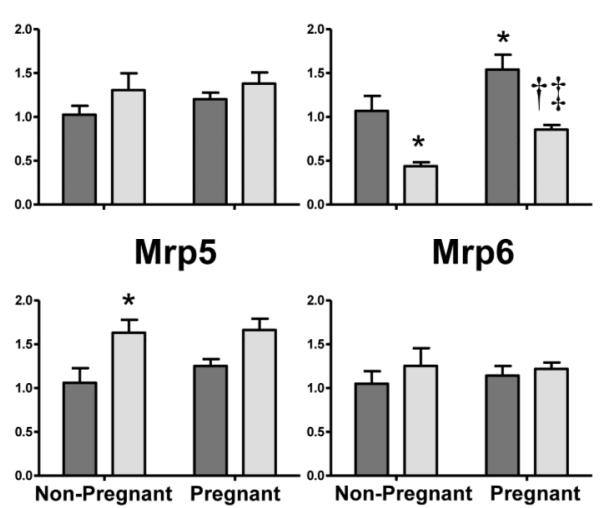

Figure 2. Renal mRNA expression of efflux transporters in vehicle- and STZ-treated mice during pregnancy

Total RNA was isolated from kidneys and mRNA levels were quantified using real-time quantitative PCR. The mRNA data for (A) apical transporters and (B) basolateral transporters are presented as means normalized to Rpl13a \pm SE ( $n=3-8$ animals). Asterisks (*) represent a statistical difference compared to vehicle non-pregnant mice ( $\mathrm{p} \leq 0.05)$; Daggers $(\dagger)$ represent a statistical difference between vehicle and STZ-treated pregnant mice ( $\mathrm{p} \leq 0.05$ ); Double daggers $(\$)$ represent a statistical difference between STZ-treated nonpregnant and pregnant mice ( $\mathrm{p} \leq 0.05$ ). 
A.

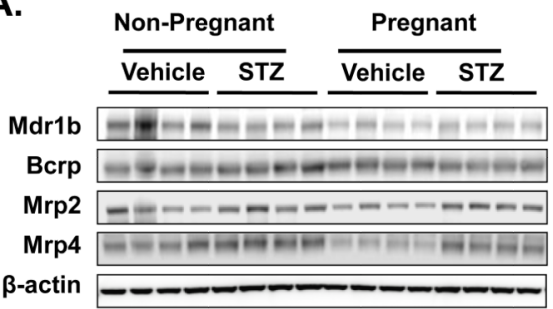

$$
\text { Mdr1b }
$$

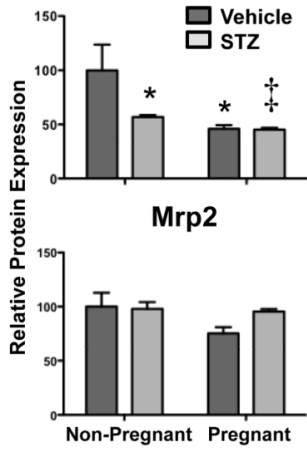

Bcrp

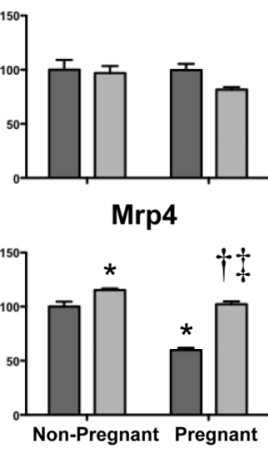

B.
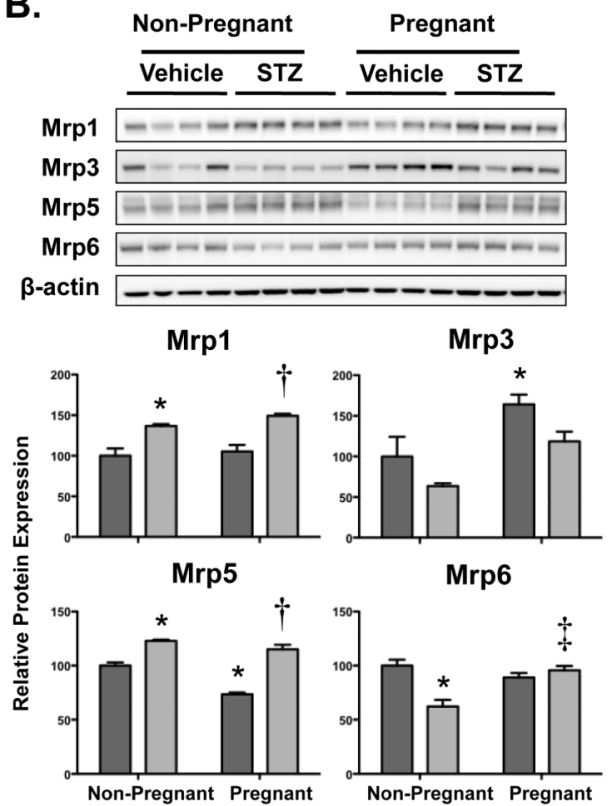

Figure 3. Renal protein expression of efflux transporters in vehicle- and STZ-treated mice during pregnancy

Immunoblots are presented for (A) apical transporters and (B) basolateral transporters in the upper portion (protein loading amount $50 \mu \mathrm{g} / \mathrm{lane}$ ). Protein band intensity was quantified by densitometry using an Alpha Innotech Fluorochem and presented as mean relative protein expression (normalized to the vehicle-treated non-pregnant experimental group) \pm SE ( $n=4$ animals). $\beta$-actin was used as a loading control. Asterisks (*) represent a statistical difference compared to vehicle non-pregnant mice $(\mathrm{p} \leq 0.05)$; Daggers $(\dagger)$ represent a statistical difference between vehicle and STZ-treated pregnant mice ( $\leq 0.05)$; Double daggers (\$) represent a statistical difference between STZ-treated non-pregnant and pregnant mice ( $\mathrm{p} \leq 0.05)$. 


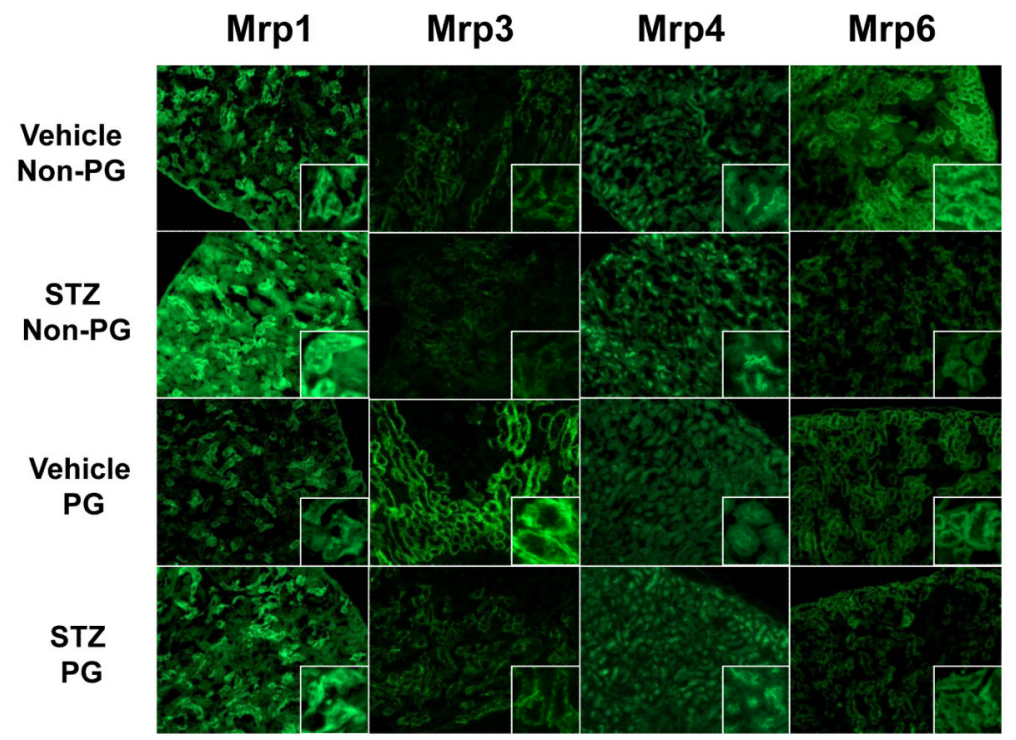

Figure 4. Immunofluorescent detection of renal Mrp1, Mrp3, Mrp4, and Mrp6 efflux transporters in vehicle- and STZ-treated mice during pregnancy

Indirect immunofluorescence staining using MRPr1, $\mathrm{M}_{3} \mathrm{II}-2, \mathrm{M}_{4} \mathrm{I}-10$, and $\mathrm{M}_{6} \mathrm{II}-68$ antibodies was conducted on kidney cryosections $(6 \mu \mathrm{m})$ obtained from gestation day 14 vehicle- and STZ-treated mice during pregnancy. Images are shown at 10X magnification. Images were cropped, enlarged, and provided as insets. 


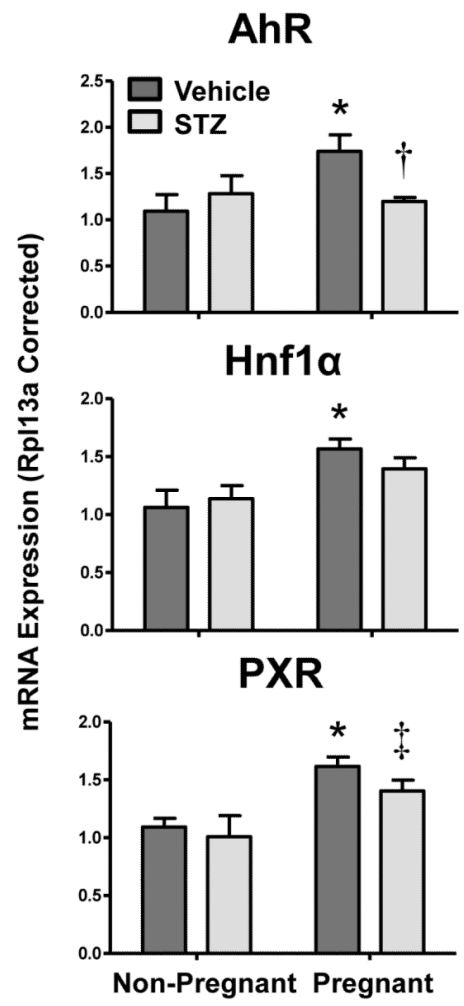

Figure 5. Renal mRNA expression of transcription factors in vehicle- and STZ-treated mice during pregnancy

Total RNA was isolated from kidneys and mRNA levels were quantified using real-time quantitative PCR. The data are presented as means normalized to Rpl13a \pm SE ( $n=3-8$ animals). Asterisks (*) represent a statistical difference compared to vehicle non-pregnant mice ( $\mathrm{p} \leq 0.05$ ); Daggers $(\dagger)$ represent a statistical difference between vehicle and STZtreated pregnant mice ( $\leq 0.05$ ); Double daggers $(\$)$ represent a statistical difference between STZ-treated non-pregnant and pregnant mice $(\mathrm{p} \leq 0.05)$. 


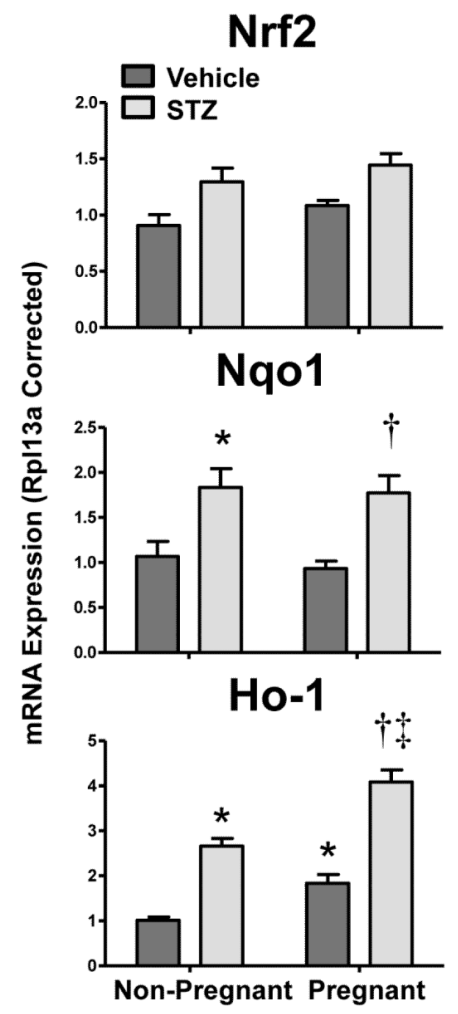

Figure 6. Renal mRNA expression of antioxidant enzymes Nqo1 and Ho-1 and the Nrf2 transcription factor in vehicle- and STZ-treated mice during pregnancy Total RNA was isolated from kidneys and mRNA levels were quantified using real-time quantitative PCR. The data are presented as means normalized to Rpl13a \pm SE ( $n=3-8$ animals). Asterisks $(*)$ represent a statistical difference compared to vehicle non-pregnant mice ( $\mathrm{p} \leq 0.05$ ); Daggers $(\dagger)$ represent a statistical difference between vehicle and STZtreated pregnant mice ( $\mathrm{p} \leq 0.05$ ); Double daggers $(\ddagger)$ represent a statistical difference between STZ-treated non-pregnant and pregnant mice $(\mathrm{p} \leq 0.05)$. 


\section{Expression of Renal Transporters}

Type I Diabetes

$\uparrow$ Mrp1 protein

$\uparrow$ Mrp2 mRNA

$\downarrow$ Mrp3 mRNA/protein

$\uparrow$ Mrp4 protein

$\uparrow$ Mrp5 mRNA/protein

$\downarrow$ Mrp6 protein

$\downarrow$ Mdr1b protein
Pregnancy

$\leftrightarrow$ Mrp1 protein

$\leftrightarrow$ Mrp2 mRNA/protein

$\uparrow$ Mrp3 mRNA/protein

$\downarrow$ Mrp4 protein

$\downarrow$ Mrp5 protein

$\leftrightarrow$ Mrp6 protein

$\downarrow$ Mdr1b protein

Figure 7. Differential expression of renal efflux transporters during diabetes and pregnancy Relative changes in mRNA and/or protein expression of efflux transporters in STZ-treated diabetic or pregnant mice are summarized. 